\title{
Momentum Trading, Contrarian Trading and Smart Money Manipulation
}

\author{
Chung-Chih Liao ${ }^{1}$ \\ ${ }^{1}$ Department and Graduate Institute of International Business, National Taiwan University, Taipei, Taiwan \\ Correspondence: Chung-Chih Liao, Department and Graduate Institute of International Business, National \\ Taiwan University, Taipei, Taiwan. E-mail: bugliao@gmail.com
}

Received: December 2, 2016

Accepted: December 22, 2016 Online Published: December 23, 2016

doi:10.5539/ibr.v10n2p53

URL: http://dx.doi.org/10.5539/ibr.v10n2p53

\begin{abstract}
There are two commonly recognized anomalies in the stock market, namely short-run momentum and long-run reversals. Under these two financial market anomalies, there are two trading strategies - momentum trading and contrarian trading - that can be adopted for the purpose of making profits. We model an asset market in which momentum traders, contrarian traders and informed rational speculators make transactions. We discovered that under certain conditions, the self-profiting motive of informed speculators will lead to their price manipulation behaviors, and result in momentum and reversals phenomenon on the asset price. We also found that the scenario of the relative quantity of the two types of behavioral traders and their profit margins is similar to that of a minority game.
\end{abstract}

Keywords: momentum, contrarian, smart money, price manipulation, heterogeneous agents

\section{Introduction}

\subsection{Introduce the Problem}

Empirical studies on the equity markets have documented two well-known stylized facts about stock returns. First, the stock returns exhibit continuation at horizons of three to twelve months, that is, returns exist unconditional positive autocorrelation in the short run. See, e.g., Jagadeesh \& Titman (1993). ${ }^{1}$ Second, stock returns are negatively autocorrelated at horizons of three to five years. See, e.g., the pioneering work of DeBondt $\&$ Thaler $(1985,1987)$. These phenomena of short-run momentum and long-run reversal of stock price can still be seen in later empirical studies. For example, see Jagadeesh \& Titman (2001) and Conrad \& Yavuz (2016). They are also commonly seen in international financial markets. See, e.g., Rouwenhorst (1998), Galariotis et al. (2007) and Doan et al. (2014), among others. Such macro empirical phenomena will provide profit margin for the two classes of traders using return-based trading strategies, namely, momentum trading and contrarian trading under respective investment time horizons. ${ }^{2}$

For micro behavior, Goetzmann and Massa (2002) directly inspected the personal trading account information of over 91,000 investors, and indeed observed the transactions by traders using momentum and contrarian strategies. Morrin et al. (2002) did research on the investment information-processing and decision-making behaviors of the professional security analysts through computer-based simulation and verbal protocol procedure. They found that the professional security analysts' decision-making process is heterogeneous, and their investment decisionmaking behaviors can indeed be classified into two trading styles: momentum and contrarian. They also did analyses on the characteristics of the two types of investors' backgrounds.

Therefore, the connection between micro behavior and macro phenomena has become an important issue for theoretical studies. The heterogeneous agent models for this kind of studies focus on the interaction between

\footnotetext{
${ }^{1}$ Besides the unconditional momentum behavior, the stock returns tend to respond sluggishly to public events and drift in the same direction as the initial event impact, see Chan et al. (1996), among others. Those observable public events include earnings announcements, IPO, etc.

${ }^{2}$ Conrad and Kaul (1998) document empirical results that the momentum strategy usually nets positive profits at relatively short (3- to 12-month) horizons, while the contrarian strategy is profitable at longer (2- to 3-year) horizons.
} 
different classes of traders through their trading behaviors in the asset markets. Particularly, we would like to understand how the trading behaviors of different types of irrational traders and rational traders decide the overall behavior of the financial markets. In the line of researches we are interested in, we want to understand the theoretical causes for the asset returns autocorrelation phenomena in empirical researches, and investigate into what role rational informed traders play in the market, whether irrational traders can persist in the market, and the interaction between rational and irrational traders.

In Hong \& Stein (1999), the model did not include fully informed traders, instead, there were several groups of newswatchers, each with different fragments of information. The information will gradually diffuse between them and lead to the underreaction in asset price, which will automatically provide an opportunity to profit for the momentum traders. The momentum traders' transactions will then excessively push up the asset price (under good news case) and lead to the overreaction by the asset price. This will finally lead to the macro phenomena of long-run reversal. DeLong et al. (1990) considered a model in which positive feedback (momentum) traders are in the market. In their model, the maximum profit for the informed rational speculators is not gained by bringing the price back to the fundamental price through arbitrage trading, instead, it is gained by 'jumping on the bandwagon', which is to further destabilize stock price, and a behavior similar to price manipulation emerges.

Slezak (2003) provided a model of an asset market where rational and irrational traders make transactions. Their irrational traders' trading strategies can create momentum and reversals in the equilibrium asset price. They showed that the phenomena of momentum and reversals will persist even in the presence of fully rational traders in the asset market. They proved that as long as rational traders are risk averse, and are faced with fundamental risk, the result above will hold. Nevertheless, little studies have considered a scenario in which momentum traders, contrarian traders and informed rational speculators who face fundamental risk are dwelt in the same platform to analyze their impacts to the risky asset price and compare their relative advantages in gaining profits. In this paper, we will fill this gap.

We will investigate into how the relative size of momentum traders and contrarian traders in the market affects the equilibrium price, and look into the possible causes that affect the profit margins for these two types of irrational traders. We surmise that as the momentum traders increase, the asset price will be continuously pushed to a same direction and overreact, and this will generate profit margin for the contrarian traders. On the contrary, when there are more and more contrarian traders, the self-interested behaviors of the rational speculators will prevent the asset price from being excessively pushed up, and lead to a macro phenomenon of underreaction by the price, and this will also allow the momentum traders to profit. In this paper, we will examine the above points.

\section{The Four-period Model}

\subsection{Assumptions}

The fundamental structure of our four-period model follows DeLong et al. (1990). We name these four periods as period $0,1,2$, and 3 . There are two assets in this economy, namely cash and one stock. We assume that cash pays no net return and exhibits infinite elasticity of supply, and normalize the net supply of the stock to be zero. Also, on the last day, which is period 3, the stock will be liquidated thoroughly and pays a single lump sum dividend of $\Phi+\theta .^{3} \theta$ is a normally distributed random shock and does not become publicly known until period 3 . We further assume that

$$
\theta \sim \mathcal{N}\left(0, \sigma_{\theta}^{2}\right)
$$

and nobody has useful or meaningful information about $\theta$ at any time before period $3 .^{4}$ By contrast with $\theta, \Phi$ can be three possible values only, i.e. $-\phi, 0$, and $\phi$, and also has an expected value of $0 .{ }^{5}$ The realized value of $\Phi$ becomes known to some informed traders in period 2, and a partially accurate signal about $\Phi$, denoted by $\varepsilon$, is sent out to those informed traders in period 1. $\Phi$ can be regarded as somewhat predictable components of the fundamental shocks for stocks in period 3.

\footnotetext{
${ }^{3}$ Since we normalize the stock to be in zero net supply, the dividend "should be thought of as side bets that investors make against one another," noted by DeLong et al. (1990).

${ }^{4}$ It can be thought of as a pure random shock of profits in the company that issues this stock.

${ }^{5}$ The realized value of $\Phi$ is determined by 'nature' according to the following probability scheme:

$$
\operatorname{Pr}(\Phi=-\phi)=0.5 q, \operatorname{Pr}(\Phi=0)=1-q \text {, and } \operatorname{Pr}(\Phi=\phi)=0.5 q .
$$

Note that $q$ is a parameter and its details will be discussed later.
} 
We have two kinds of traders included in our model, namely informed rational speculators and behavioral traders. The informed rational speculators, denoted by " $r$ ", are present in a measure of 1 , and they seek to maximize their next-period utility of wealth in a mean-variance form:

$$
\mathcal{U}\left(W_{t+1}\right)=\mathrm{E}_{t}\left(W_{t+1}\right)-\gamma \operatorname{Var}_{t}\left(W_{t+1}\right)
$$

Note that $\gamma$ denotes the risk aversion coefficient and $W_{t+1}$ the next-period wealth. By solving this maximization problem, the informed speculators form their demand for stocks in period $t$, denoted by $D_{t}^{r}$.

As mentioned earlier, the informed speculators receive a noisy signal $\varepsilon \in\{\phi,-\phi\}$ about $\Phi$ in period 1 . We assume that the following probability matrix gives the joint probability of $\Phi$ and $\varepsilon$.

\begin{tabular}{|c|c|c|c|}
\hline \multirow[b]{2}{*}{$\operatorname{Pr}(\Phi, \varepsilon)$} & \multicolumn{3}{|c|}{$\Phi$} \\
\hline & $-\phi$ & 0 & $\phi$ \\
\hline$\phi$ & 0 & $0.5(1-q)$ & $0.5 q$ \\
\hline$-\phi$ & $0.5 q$ & $0.5(1-q)$ & 0 \\
\hline
\end{tabular}

When the informed speculators received $\varepsilon$ that equals to $\phi$, the realized value of $\Phi$ will be $\phi$ or 0 , determined by the following conditional probabilities:

$$
\operatorname{Pr}(\Phi=\phi \mid \varepsilon=\phi)=q \text { and } \operatorname{Pr}(\Phi=0 \mid \varepsilon=\phi)=1-q .
$$

As a result, the expected value of $\Phi$ is $q \phi$ conditional on $\varepsilon=\phi$. Nevertheless, when they received $\varepsilon$ that equals to $-\phi$, the conditional probabilities are given by

$$
\operatorname{Pr}(\Phi=0 \mid \varepsilon=-\phi)=1-q \text { and } \operatorname{Pr}(\Phi=-\phi \mid \varepsilon=-\phi)=q .
$$

The informed speculators can thus make their investment decisions based on this informative signal. Note that $q$ is a parameter that represents the precision of the noisy signal, $\varepsilon .^{6}$

Behavioral traders trade risky assets solely based on the price change in the previous periods. They are present in a measure of $\lambda$ and have two phenotypes, say, momentum traders, denoted by " $m$ ", and contrarian traders, denoted by " $c$ ". The ratio of momentum traders to contrarian traders is set to be $\mu$ and $1-\mu$. Momentum traders incline to chase a trend by buying after prices rise and selling after prices fall, and contrarians do the opposite. Following the empirical evidence in the literature, we assume that the momentum traders' demand for the stock responds to the price change across one period of time. Whereas the contrarian traders look through a longer time horizon and base their trading strategies on the price changes across two periods of time. According to the trading rule momentum traders adopt, their demand for stocks in period $t$ is given by

$$
D_{t}^{m}=\beta\left(P_{t}-P_{t-1}\right)
$$

where $P_{t}$ is the stock price in period $t$ and $\beta>0$. In sharp contrast to momentum traders, contrarian traders' demand for stock in period $t$ is set to be

where $\alpha>0$.

$$
D_{t}^{c}=-\alpha\left(P_{t}-P_{t-2}\right)
$$

Note that, in period 0 and 3, there is no trading. We allow informed speculators and momentum traders to trade in period 1 and 2, whereas contrarians trade only in period 2. Since there is no trading in period 0 , we set the period 0 stock price to be its initial fundamental value of zero, which is $P_{0}=0$. This is an important benchmark period for the behavioral traders to refer to, because at times they form their demands for stocks according to the appreciation or depreciation of stocks from period 0 to periods 1 or 2 . We summarize the fundamental structure of our four-period model and the total demands of traders of different kinds in Table $1 .^{7}$

\subsection{Solving the Model}

Following the same logic that DeLong et al. (1990) used to tackle this four-period model, we solve it from period 3 backwards. We consider the case that a positive signal is received by informed speculators in period 1, that is,

\footnotetext{
${ }^{6}$ When $q$ approaches 1 , the informed speculators can somewhat become certain that $\Phi=\phi$ will happen as they get the signal $\varepsilon=\phi$. Similarly, when $q$ approaches 0 , the informed speculators realize that as they get the signal $\varepsilon=\phi$, then $\Phi=0$ will very likely be the case. On the contrary, a $q$ whose value is around 0.5 implies that the signal the informed speculators get is less precise.
}

${ }^{7}$ This table is adapted from the Table 1 in DeLong et al. (1990), p. 385. 
Table 1. Structure of the four-period model

\begin{tabular}{|c|c|c|c|c|c|}
\hline \multirow[b]{2}{*}{ Period } & \multirow[b]{2}{*}{ Event } & \multicolumn{3}{|c|}{ Total Demands of: } & \multirow[b]{2}{*}{ Price } \\
\hline & & $\begin{array}{l}\text { Momentum } \\
\text { Traders }\end{array}$ & $\begin{array}{l}\text { Contrarian } \\
\text { Traders }\end{array}$ & $\begin{array}{c}\text { Informed } \\
\text { Speculators }\end{array}$ & \\
\hline 0 & $\begin{array}{l}\text { Reference period, no signals are } \\
\text { received }\end{array}$ & 0 & 0 & 0 & $P_{0}=0$ \\
\hline 1 & $\begin{array}{l}\text { Speculators receive a signal } \varepsilon \text { of } \\
\text { the period } 2 \text { fundamental shock } \Phi\end{array}$ & $\beta\left(P_{1}-P_{0}\right)$ & 0 & $D_{1}^{r}$ & $P_{1}$ \\
\hline 2 & Speculators learn $\Phi$ & $\beta\left(P_{2}-P_{1}\right)$ & $-\alpha\left(P_{2}-P_{0}\right)$ & $D_{2}^{r}$ & $P_{2}$ \\
\hline 3 & $\begin{array}{l}\text { Liquidation: dividend } \Phi+\theta \\
\text { declared }\end{array}$ & 0 & 0 & 0 & $P_{3}=\Phi+\theta$ \\
\hline
\end{tabular}

$\varepsilon=\phi .{ }^{8}$ As shown in Equation (4), this implies that $\Phi$ can be $\phi$ or 0 with probabilities of $q$ and $1-q$, respectively. For the ease of depiction, we name the uncertainty state in which $\Phi=\phi$ as state $a$ and $\Phi=0$ as state $b$. In the final period, the stock is liquidated thoroughly, and hence its value (price) equals to the lump sum dividend it pays, which is $\Phi+\theta$. To put it specifically,

$$
\begin{aligned}
& P_{3 a}=\phi+\theta, \text { and } \\
& P_{3 b}=\theta
\end{aligned}
$$

In period 2, informed speculators learn the true value of $\Phi$ one period in advance. They then seek to maximize his period 3 utility, i.e. $\mathcal{U}\left(W_{3}\right)$ in Equation (3), subject to his period 3's wealth constraint:

$$
W_{3}=D_{2}^{r}\left(\Phi+\theta-P_{2}\right)
$$

By solving this maximization problem, we get the period 2 stock demand function for informed speculators shown as

$$
D_{2}^{r}=c\left(\Phi-P_{2}\right)
$$

where $c=1 /\left(2 \gamma \sigma_{\theta}^{2}\right)$. In order to solve the equilibrium period 2 stock prices, we are now ready to plug demand functions of all traders into the period 2 equilibrium condition:

$$
\lambda\left(\mu D_{2}^{m}+(1-\mu) D_{2}^{c}\right)+D_{2}^{r}=0 .
$$

Note that the stock is assumed to be in zero net supply by assumption. For states $2 a$ and $2 b$, respectively, we have

$$
\begin{aligned}
& \lambda \mu \beta\left(P_{2 a}-P_{1}\right)-\lambda(1-\mu) \alpha\left(P_{2 a}-P_{0}\right)+c\left(\phi-P_{2 a}\right)=0, \text { and } \\
& \lambda \mu \beta\left(P_{2 b}-P_{1}\right)-\lambda(1-\mu) \alpha\left(P_{2 b}-P_{0}\right)+c\left(0-P_{2 b}\right)=0
\end{aligned}
$$

By rearranging the terms, we obtain the market clearing stock prices in states $2 a$ and $2 b$, i.e.,

$$
\begin{gathered}
P_{2 a}=\frac{-\lambda \mu \beta}{c-\lambda \mu \beta+\lambda(1-\mu) \alpha} P_{1}+\frac{c}{c-\lambda \mu \beta+\lambda(1-\mu) \alpha} \phi, \quad \text { and } \\
P_{2 b}=\frac{-\lambda \mu \beta}{c-\lambda \mu \beta+\lambda(1-\mu) \alpha} P_{1} .
\end{gathered}
$$

These period 2 stock prices, as we have seen, depend on the period 1 price. In other words, they are path-dependent.

The next step is to solve for the period 1 stock price. To do this, we have to determine the informed speculators' period 1 stock demand function $D_{1}^{r}$ in advance. In period 1, informed speculators face a problem of maximizing their period 2 mean-variance utility, which is $\mathcal{U}\left(W_{2}\right)$ in Equation (3). Note that speculators' period 2 wealth is

$$
W_{2}=D_{1}^{r}\left(P_{2}-P_{1}\right)+\mathrm{CE}_{W_{3}},
$$

\footnotetext{
${ }^{8}$ However, owing to the symmetric setting we make, the case of $\varepsilon=-\phi$ will behave much like a 'reflection' of what will be discussed.
} 
where $\mathrm{CE}_{W_{3}}$ denotes informed speculators' perceived certain-equivalent wealth of period $3 .^{9}$ After solving informed speculators' optimum period 1 stock demand $D_{1}^{r}$, we are ready to get the solution for the period 1 market clearing stock price. Owing to the fact that contrarian traders do not trade in period 1, the period 1 market clearing condition is given by

$$
\lambda \mu D_{1}^{m}+D_{1}^{r}=0,
$$

where $D_{1}^{m}=\beta\left(P_{1}-P_{0}\right)$ and $P_{0}=0$. We state the solution for the period 1 stock price in Proposition 1 and the proof is given in the Appendix.

Proposition 1. In the case of a positive signal, i.e. $\varepsilon=\phi$, the period 1 stock price is

$$
P_{1}=q \phi \cdot \frac{c\left[(c-\lambda \mu \beta+\lambda(1-\mu) \alpha)^{2}-c(1-q) \gamma \phi^{2}(\lambda \mu \beta-\lambda(1-\mu) \alpha)^{2}\right]}{(c+\lambda(1-\mu) \alpha)(c-\lambda \mu \beta+\lambda(1-\mu) \alpha)^{2}-2 c^{3} q(1-q) \gamma \lambda \mu \beta \phi^{2}}
$$

When there are no behavioral traders in the markets, i.e. $\lambda=0$, the period 1 stock price will be equivalent to the 'fundamental price' of $P_{1}=q \phi$.

Proof. See Appendix.

\section{Results and Discussion}

\subsection{Profit Functions for the Traders}

We now can analyze the behavior of equilibrium stock prices and the profits for the traders. The following equation is the profit function for the informed rational speculators,

$$
\pi^{r}=D_{1}^{r}\left(P_{2}-P_{1}\right)+D_{2}^{r}\left(\Phi+\theta-P_{2}\right)
$$

whereas the profit functions for the momentum traders and the contrarian traders, denoted by $\pi^{m}$ and $\pi^{c}$, respectively, are given by

$$
\begin{aligned}
\pi^{m} & =D_{1}^{m}\left(P_{2}-P_{1}\right)+D_{2}^{m}\left(\Phi+\theta-P_{2}\right) \\
& =\beta P_{1}\left(P_{2}-P_{1}\right)+\beta\left(P_{2}-P_{1}\right)\left(\Phi+\theta-P_{2}\right) \text { and } \\
\pi^{c} & =D_{2}^{c}\left(\Phi+\theta-P_{2}\right)=-\alpha P_{2}\left(\Phi+\theta-P_{2}\right) .{ }^{10}
\end{aligned}
$$

Owing to the highly complicated nature of Equation (19), we use numerical analysis as an alternative to equilibriums stock prices $\left(P_{2 a}, P_{2 b}\right.$ and $\left.P_{1}\right)$ and traders' expected profits $\left(\bar{\pi}^{r}, \bar{\pi}^{m}\right.$ and $\left.\bar{\pi}^{c}\right)$ under some sets of parameters to see how the exogenous parameters could affect them. Although the results we reveal here are for a limited set of parameters, they can also represent the results obtained under other reasonable assumptions of parameters.

\subsection{Effects on the Popularity of Behavioral Traders}

We first examine how the popularity of the two sorts of behavioral trading strategies, i.e., momentum trading and contrarian trading, could affect the equilibrium stock prices and the profits for all the traders. Figure 1 presents the results and shows the following properties.

Property 1. As the momentum traders increase, i.e., $\mu$ increases, the period 1 stock price, $P_{1}$, also increase $\left(P_{1}\right.$ is increasing in $\mu$ ). Under that circumstance, the profits the contrarian traders can earn gets higher $\left(\bar{\pi}^{c}\right.$ is increasing in $\mu$ ), while that for the momentum traders gets lower $\left(\bar{\pi}^{m}\right.$ is decreasing in $\mu$ ). As the contrarian traders increase, i.e., $\mu$ decreases, it has an opposite effect.

When there are more people with a specific kind of 'trading thoughts' in the market, the profit margin for those who adopt such strategy will be compressed, while using the other trading strategy provides profitability. ${ }^{11}$ In Figure 1, we can also see that as the relative popularity of behavioral traders to informed speculators increases, i.e., $\lambda$ increases, the effect of the above mentioned Property 1 becomes stronger.

\footnotetext{
${ }^{9}$ Informed speculators' period 2 wealth is composed of two distinct parts. First, by holding the stock from period 1 to period 2, informed speculators enjoy the capital gains (or losses). Second, the investment opportunities available to informed speculators in period 2 are definitely worth some value and are priced at period 2 certain-equivalent wealth of them.

${ }^{10}$ Hereafter, we will denote by $\bar{\pi}^{r}, \bar{\pi}^{m}$ and $\bar{\pi}^{c}$ the expected value of the profits for traders.

${ }^{11}$ If each of the behavioral traders could choose his/her trading strategy between trend-chasing and contrarian before participating in the trades. The behavioral traders will become part of a minority game in financial markets. A number of studies have investigated into this matter. See, e.g., Challet et al. (2014) for reference.
} 

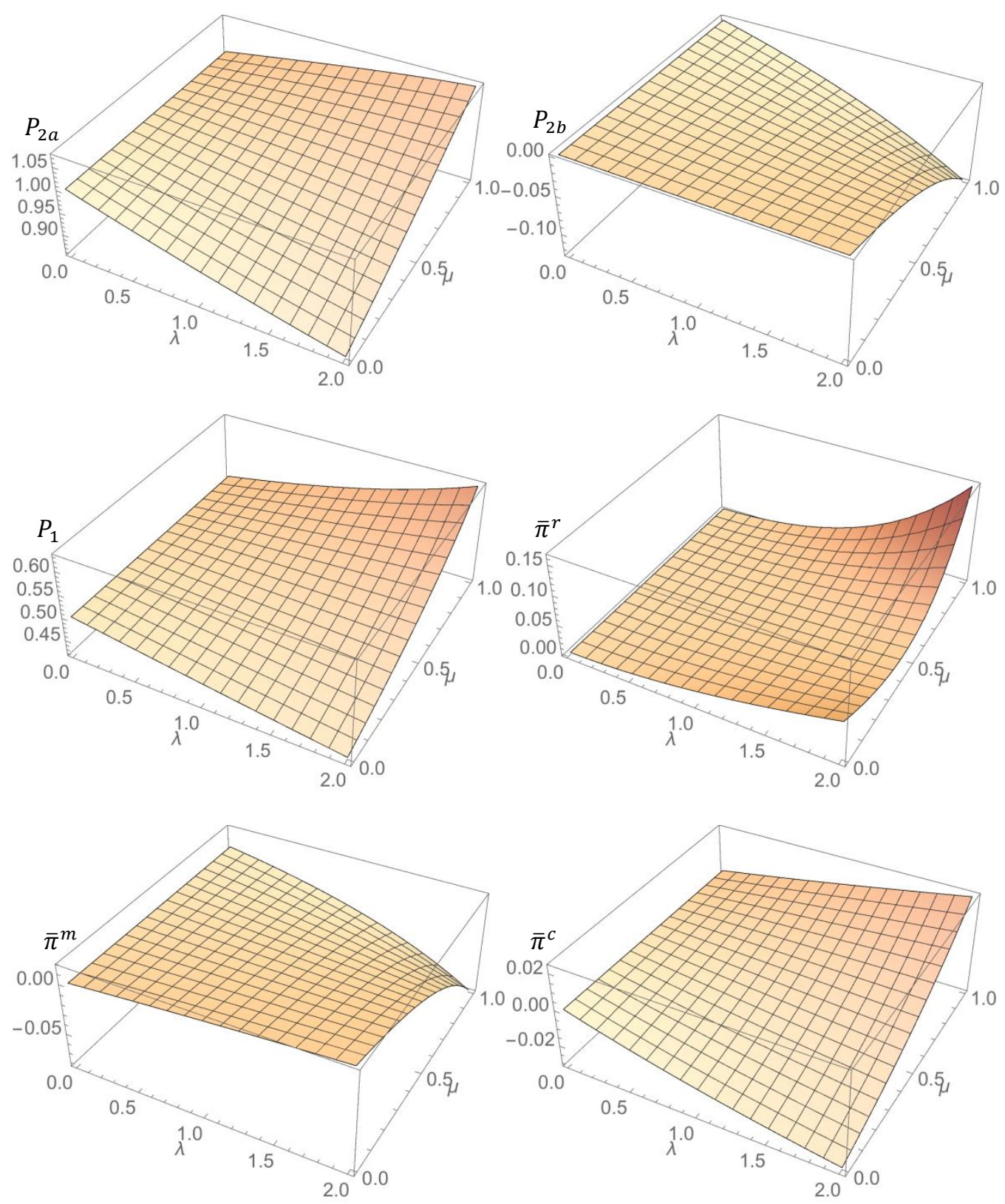

Figure 1. Equilibrium $P_{2 a}, P_{2 b}, P_{1}, \bar{\pi}^{r}, \bar{\pi}^{m}$ and $\bar{\pi}^{c}$ as a Function of $\lambda$ and $\mu$

Note. We adopt the following parameter settings for the numerical results shown in Figure 1: $\phi=1, \sigma_{\theta}=0.5$, $\gamma=1 / 3, \beta=0.5, \alpha=0.5$ and $q=0.5$.

Under this set of parameters, notice that when there are no behavioral traders in the markets, i.e., $\lambda=0$, the period 1 stock price will be equivalent to the 'fundamental price' of $P_{1}=q \phi=0.5$. When there are behavioral traders, i.e., $\lambda>0$, as the momentum traders increases, which is when $\mu$ increases, the momentum traders will push the period 1 stock price up, making $P_{1}>0.5$, which is quite instinctive. Surprisingly, following the increase in contrarian traders, i.e., the decrease in $\mu$, we find that $P_{1}<0.5$. Recall that contrarian traders are not involved in the period 1 trading. In the case of $\mu \ll 0.5$, the period 1 stock price is primarily settled by informed speculators. This makes it necessary for us to further discuss whether the equilibrium stock price in period 1 is partly determined by the informed speculators' trade-based price manipulation conduct. $^{12}$

\footnotetext{
${ }^{12} \mathrm{By}$ trade-based manipulation, we refer to manipulators manipulating the asset price merely by buying the asset and selling it or vice versa. In contrast, action-based manipulation is defined as a group of traders seeking to interfere in the asset value by releasing misleading information or conducting publicly observable actions. Nevertheless, in order to maintain the trading order in the market, most of the countries control and limit
} 


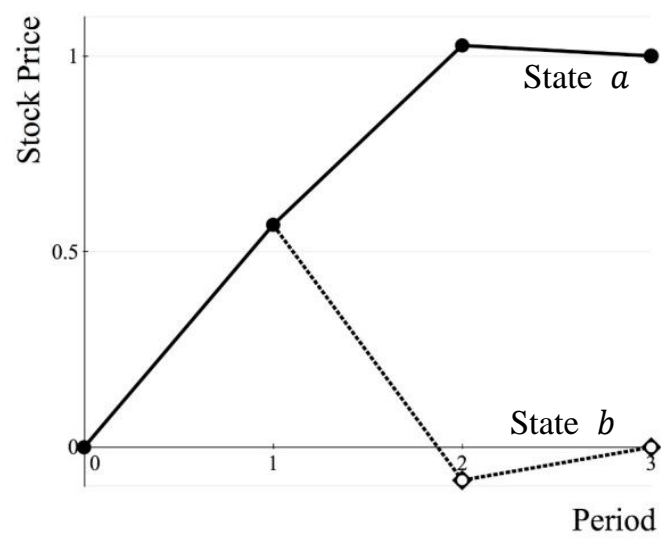

(a) $\mu=0.8$

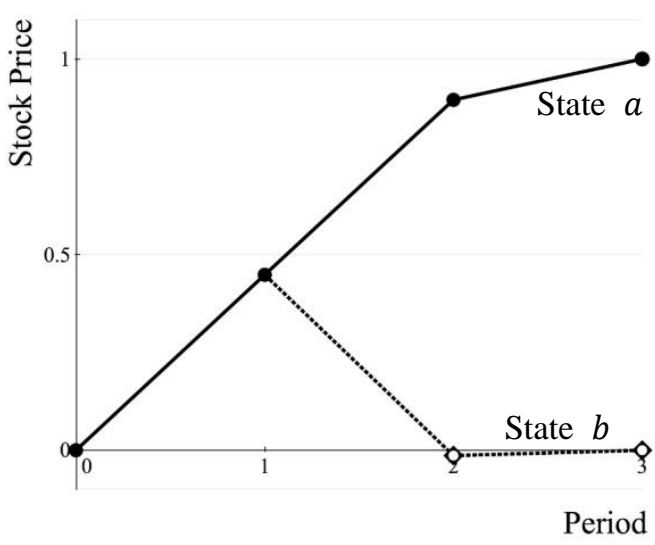

(b) $\mu=0.2$

Figure 2. Equilibrium Prices Dynamics

Note. We adopt the following parameter settings for the numerical results shown in Figure 2: $\phi=1, \sigma_{\theta}=0.5$, $\gamma=1 / 3, \beta=0.5, \alpha=0.5, q=0.5$ and $\lambda=2$.

Figure 2 shows the dynamics of equilibrium prices. We begin by discussing the case with relatively more momentum traders in the market, e.g., $\mu=0.8$. See Figure 2(a). Period 1 stock price, $P_{1}$, has been pushed above the 'fundamental price' of $q \phi=0.5$. When time moves to period 2 where state $2 a$ occurs, informed speculators notice $\Phi=\phi=1, P_{2 a}$ is also pushed above 'fundamental price' of $\phi=1$. At this time, the trend trades by the momentum traders in period 2 will lead to losses. When state $2 b$ occurs, informed speculators get to know that $\Phi=\phi=0$, we observe that $P_{2 b}$ is brought down by informed speculators to below 'fundamental price' of $\phi=0$. At this time, the trend trades by the momentum traders in period 2 will also lead to losses. Meanwhile, contrarian traders can also benefit from it.

We continue to discuss the case where there are relatively more contrarian traders $(\mu=0.2)$. See Figure 2(b). The equilibrium trading price of Period 1 stock, $P_{1}$, is lower than the 'fundamental price' of $q \phi=0.5$. When state $2 a$ of period 2 occurs, $P_{2 a}$ also becomes lower than 'fundamental price' of $\phi=1$. This situation is to some degree resulted from the risk averse nature of the informed speculators, because period 3 payoff $\phi+\theta$ has the unknown component $\theta .^{13}$ However, we can still infer that when the informed speculators realize that there are a large number of contrarian traders in the market, this price manipulation conduct can lead to the contrarian traders' losses and in turn benefit themselves. Such trade-based price manipulation also leads to the results in property 2 .

Property 2. Informed speculators' profit margin increases by the increase in the momentum traders in the market. (When $\mu>0.5, \bar{\pi}^{r}$ increase as $\mu$ increase.) It also increases following the increase in the number of the contrarian traders. (When $\mu<0.5, \bar{\pi}^{r}$ increase as $\mu$ decrease.)

Rational informed-speculators make use of the behavioral traders' transactions in manipulating the price to profit. Mei et al. (2004) have also modeled how smart money has similar trade-based price manipulation conduct. If, in the market, there are behavioral traders who exhibit disposition effect, which is an anomalous trading behavior where winners are sold sooner and losers later, the manipulator in their model can profit by pushing the asset price up, and then selling the asset at high prices afterwards.

Compared to Hong \& Stein (1999), we have similar results that momentum traders' trend-chasing trades lead to the market price overreaction phenomena, as shown in figure 2(a). However, in our model, the market price underreaction is not derived from the gradual diffusion of information across informed traders, instead, it resulted from the existence of irrational contrarian traders in the market, which lead to the price manipulation behaviors of the rational informed speculators, as shown in figure 2(b).

\section{Conclusion}

Short-run momentum and long-run reversals are two commonly recognized anomalies in the stock markets.

action-based manipulation through legislation.

${ }^{13}$ If we reduce the variability parameter of $\theta$, i.e., $\sigma_{\theta}$, we will find that $P_{1}$ is closer to 0.5 , and $P_{2 a}$ is closer to 1, but we still have $P_{1}<0.5$ and $P_{2 a}<1$. 
Momentum trading and contrarian trading are two trading strategies to make profits under the above two financial markets anomalies. We can also find in researches on individual traders that these two trading strategies are commonly adopted. Is it the existence of macro phenomena that lead to the traders' micro behaviors for profiting? Or, does the macro phenomena of special anomalies exist because the micro-behaviors aggregate and interact with each other? This has always been an issue researchers would like to figure out.

Most of the past literature consider the gradual flow of information as the cause to the underreaction of stock price and momentum. Moreover, the existence of momentum traders has also been taken as the reason for the overreaction of stock price, and as a result reversals. In our model, we raise a different possibility. Rational speculators become aware of the existence of different types of behavioral traders in the market, and with self-profiting as their motive, they manipulate the asset price, and lead to the macro phenomena of momentum and reversals. When the quantity of momentum traders is relatively high, rational speculators will try to 'jump on the bandwagon', and they will choose to not bring the price back to fundamental price and give rise to an overreaction by the asset price. Conversely, when there are relatively more contrarian traders in the market, because of the existence of fundamental risk, even when good news appears, the rational speculators will avoid the excessive push-up stock price, and result in an underreaction phenomena.

Moreover, it has been commonly confirmed in past literature that provided that the rational traders are faced with a market with fundamental risk, these anomalies will not vanish because of arbitrage behaviors. We can also see this in our model. In our model, we point out additionally, that if each of the behavioral traders could choose his/her trading strategy between trend-chasing and contrarian before participating in the trades. The behavioral traders will become part of a minority game in financial markets. When there are more people with a specific kind of 'trading thoughts' in the market, the profit margin for those who adopt such strategy will be compressed, while using the other trading strategy provides profitability. We can also change the model to allow behavioral traders to switch between momentum and contrarian strategies based on the incentive to struggle for existence, and through this we can observe the dynamic behavior of market phenomenon and profit margins for the traders. This is a feasible direction for future research.

\section{References}

Challet, D., Marsili, M., \& Zhang, Y. C. (2014). Minority Games: Interacting agents in financial markets. Oxford, UK: Oxford University Press

Chan, L. K. C., Jagadeesh, N., \& Lakonishok, J. (1996). Momentum strategies. Journal of Finance, 51, 1681-1713. https://doi.org/10.1111/j.1540-6261.1996.tb05222.x

Conrad, J., \& Kaul, G. (1998). An anatomy of trading strategies. Review of Financial Studies, 11, 489-519. https://doi.org/10.1093/rfs/11.3.489

Conrad, J., \& Yavuz, M. D. (2016). Momentum and reversal: Does what goes up always come down? Review of Finance, Advance Access published March 15, 2016. https://doi.org/10.1093/rof/rfw006

DeBondt, W. F. M., \& Thaler, R. H. (1985). Does the stock market overreact? Journal of Finance, 40, 793-808. https://doi.org/10.1111/j.1540-6261.1985.tb05004.x

DeBondt, W. F. M., \& Thaler, R. H. (1987). Further evidence on investor overreaction and stock market seasonality, Journal of Finance, 42, 557-581. https://doi.org/10.1111/j.1540-6261.1987.tb04569.x

DeLong, J. B., Shleifer, A., Summers, L.H., \& Waldmann, R. J. (1990). Positive feedback investment strategies and destabilizing rational speculation. Journal of Finance, 45, 375-395.

Doan, M. P., Alexeev, V., \& Brooks, R. (2014). Concurrent momentum and contrarian strategies in the Australian stock market. Australian Journal of Management, 41, 77-106. https://doi.org/10.1177/0312896214534864

Galariotis, E. C., Holmes, P., \& Ma, X. S. (2007). Contrarian and momentum profitability revisited: Evidence from the London Stock Exchange 1964-2005. Journal of Multinational Financial Management, 17, 432-447. https://doi.org/10.1016/j.mulfin.2007.01.003

Goetzmann, W. N., \& Massa, M. (2002). Daily momentum and contrarian behavior of index fund investors. Journal of Financial and Quantitative Analysis, 37, 375-389. https://doi.org/10.2307/3594985

Hong, H., \& Stein J. C. (1999). A unified theory of undereaction, momentum trading, and overreaction in asset markets. Journal of Finance, 54, 2143-2184. https://doi.org/10.1111/0022-1082.00184

Jagadeesh, N., \& Titman, S. (1993). Returns to buying winners and selling losers: Implications for stock market efficiency. Journal of Finance, 48, 65-91. https://doi.org/10.1111/j.1540-6261.1993.tb04702.x 
Jagadeesh, N., \& Titman, S. (2001). Profitability of momentum strategies: An evaluation of alternative explanations. Journal of Finance, 56, 699-720. https://doi.org/10.1111/0022-1082.00342

Mei, J., Wu, G., \& Zhou, C. (2004). Behavior based manipulation: Theory and prosecution evidence. Available at SSRN: http://dx.doi.org/10.2139/ssrn.457880

Morrin, M., Jacoby, J., Johar, G. V., He, X., Kuss, A., \& Mazursky, D. (2002). Taking stock of stockbrokers: Exploring momentum versus contrarian investor. Journal of Consumer Research, 29, 188-198. https://doi.org/10.1086/341570

Rouwenhorst, K. G. (1998). International Momentum Strategies. Journal of Finance, 53, 267-284. https://doi.org/10.1111/0022-1082.95722

Slezak, S. L. (2003). On the impossibility of weak-form efficient markets. Journal of Financial and Quantitative Analysis, 38, 523-554. https://doi.org/10.2307/4126730 


\section{Appendix: Proof of Proposition 1}

First of all, we calculate the perceived certain-equivalence wealth of period 3 in the states $a$ and $b$, in other words, $\mathrm{CE}_{W_{3} a}$ and $\mathrm{CE}_{W_{3 b}}$. Combining Equations (10) and (11) we have

$$
\begin{aligned}
W_{3 a} & =D_{2}^{r}\left(\phi+\theta-P_{2 a}\right) \\
& =c\left(\phi-P_{2 a}\right)\left(\phi+\theta-P_{2 a}\right), \text { and } \\
W_{3 b} & =D_{2}^{r}\left(0+\theta-P_{2 b}\right) \\
& =c\left(0-P_{2 b}\right)\left(0+\theta-P_{2 b}\right) .
\end{aligned}
$$

Recall that $\Phi=\phi$ in states $a$, and $\Phi=0$ in states $b$. By putting the period 3 'random' wealth into informed speculators' mean-variance utility function of Equation (3), we get the certain-equivalence wealth of period 3. In state $3 a$, the result is

$$
\begin{aligned}
\mathrm{CE}_{W_{3 a}} & =\mathrm{E}\left(W_{3 a}\right)-\gamma \operatorname{Var}\left(W_{3 a}\right) \\
& =c\left(\phi-P_{2 a}\right)^{2}-\gamma c^{2}\left(\phi-P_{2 a}\right)^{2} \sigma_{\theta}^{2} \\
& =\frac{1}{2} c\left(\phi-P_{2 a}\right)^{2},
\end{aligned}
$$

where $\mathrm{E}(\theta)=0$ and $\operatorname{Var}(\theta)=\sigma_{\theta}^{2}$ by assumptions, and we use the fact that $c=1 /\left(2 \gamma \sigma_{\theta}^{2}\right)$. For the same reason, the certain-equivalence wealth of state $3 b$ is

$$
\mathrm{CE}_{W_{3 b}}=\frac{1}{2} c\left(0-P_{2 b}\right)^{2}=\frac{1}{2} c P_{2 b}^{2} .
$$

We now proceed to solve the optimization problem faced by informed speculators in period 1 , and calculate their period 1 stock demand function, i.e., $D_{1}^{r}$. From Equations (17), (25), and (26), we know that

$$
\begin{aligned}
& W_{2 a}=D_{1}^{r}\left(P_{2 a}-P_{1}\right)+\frac{1}{2} c\left(\phi-P_{2 a}\right)^{2}, \text { and } \\
& W_{2 b}=D_{1}^{r}\left(P_{2 b}-P_{1}\right)+\frac{1}{2} c P_{2 b}^{2} .
\end{aligned}
$$

We should notice that we have already solved the stock prices of states $2 a$ and $2 b$, as shown in Equations (15) and (16), so we can simply plug them into Equations (27) and (28). In period 1, informed speculators seek to maximize their mean-variance utility function, that is

$$
\mathcal{u}\left(W_{2}\right)=\mathrm{E}\left(W_{2}\right)-\gamma \operatorname{Var}\left(W_{2}\right)
$$

where

$$
\mathrm{E}\left(W_{2}\right)=q W_{2 a}+(1-q) W_{2 b}
$$

and

$$
\operatorname{Var}\left(W_{2}\right)=q\left(W_{2 a}-\mathrm{E}\left(W_{2}\right)\right)^{2}+(1-q)\left(W_{2 b}-\mathrm{E}\left(W_{2}\right)\right)^{2} .
$$

Recall from Equation (4) that conditional on a positive signal received by informed speculators, which is $\varepsilon=\phi$, state $2 a$ occurs with probability $q$, and state $2 b$ occurs with probability $1-q$. The first-order condition for maximizing Equations (29) gives the optimal $D_{1}^{r}$. (For it is a rather complicated equation, we do not show it up here.) By substituting it into the period 1 market clearing condition, as shown in Equation (18), we have

$$
\lambda \mu \beta P_{1}+D_{1}^{r}=0 .
$$

Now we get the period 1 equilibrium stock price by rearranging the terms:

$$
P_{1}=q \phi \cdot \frac{c\left[(c-\lambda \mu \beta+\lambda(1-\mu) \alpha)^{2}-c(1-q) \gamma \phi^{2}(\lambda \mu \beta-\lambda(1-\mu) \alpha)^{2}\right]}{(c+\lambda(1-\mu) \alpha)(c-\lambda \mu \beta+\lambda(1-\mu) \alpha)^{2}-2 c^{3} q(1-q) \gamma \lambda \mu \beta \phi^{2}}
$$

Finally, by simply imposing the condition of $\lambda=0$ on the above equilibrium price equation, we have $P_{1}=q \phi$.

$Q E D$

\section{Copyrights}

Copyright for this article is retained by the author(s), with first publication rights granted to the journal.

This is an open-access article distributed under the terms and conditions of the Creative Commons Attribution license (http://creativecommons.org/licenses/by/4.0/). 